\title{
Genetic divergence in pumpkin (Cucurbita Moschata Duch Ex Poir)
}

\begin{abstract}
A Field experiment was conducted in Research and Development farm of Lal Teer Seed Ltd. to estimate the genetic divergence among the 21 genotypes of pumpkin were estimated using D2 and principal component analyses. The genotypes under study grouped in to six clusters. The inter-cluster distance was larger than the intracluster distance suggesting wider genetic diversity among the genotypes of different groups. The intra-cluster value was maximum in cluster VI and minimum in cluster III. The maximum inter cluster distance average D2 value was observed between cluster I and cluster III (25.75) indicating wide range of genetic diversity between these two clusters. Thus the genetically diverged genotypes could be used as parent in hybridization program for getting desirable segregants. The lowest inter cluster divergence was observed between cluster III and IV (7.14). Cluster I showed the lowest mean values for days to first male and female flowering and highest mean values for flesh thickness, number of seeds per fruit and brix (\%), while cluster VI revealed the highest mean vales for fruit diameter, single fruit weight and yield per plant. Germplasms much in use of the above mentioned characters both in cluster I and VI would offer a good scope of improvement of the crop through rational selection for hybrid breeding program.
\end{abstract}

Volume 4 Issue 5 - 2016

\author{
Mohsin GM, ${ }^{2}$ Islam, MS,' Rahman MS, ${ }^{3}$ \\ Hasanuzzaman M, ${ }^{4}$ Biswas $\mathrm{BK}^{4}$ \\ 'Senior Plant Breeder, BRAC Seed \& Agro, Bangladesh \\ ${ }^{2}$ Department of Agriculture, Noakhali Science and Technology \\ University, Bangladesh \\ ${ }^{3}$ Plant Breeder, Lal Teer Seed Limited, Bangladesh \\ ${ }^{4}$ Department of GPB, HSTU, Bangladesh
}

Correspondence: Md Shafiqul Islam, Senior Plant Breeder,
BRAC Seed \& Agro, Gazipur, Bangladesh Email shafiq.kbd@gmail.com

Received: September 21, 2016 | Published: October 12, 2016

Keywords: pumpkin, genetic diversity, cluster analysis

\section{Introduction}

Pumpkin (Cucurbitamoschata Duch. Ex. Poir) is the most important seed propagated monoecious climbing vegetable crop that belongs to the family Cucurbitaceae, with the chromosome number $2 \mathrm{n}=40 .{ }^{1}$ It is one of the most common fruit vegetables in Bangladesh. It is locally known as "Misty kumra" or "Misty lau" or "Misty kadu". ${ }^{2}$ Being a most common nutritional rich crop scientific attempt is needed for its genetic improvement. Multivariate analysis is a useful tool in quantifying the degree of divergence between biological population at genotypic level and in assessing relative contribution of different components to the total divergence both at intra and inter-cluster levels..$^{3-6}$ Such a study also permits to select the genetically divergent parents to obtain the desirable recombinant in the segregating generations upon crossing. The present study was therefore undertaken to analyze the genetic divergence of 21 pumpkin genotypes collected from Bangladesh and Asia pacific.

\section{Materials and methods}

The twenty one diverse germplasms of pumpkin (Table 1) collected from different parts of the country, Lal Teer Seed, BARI, AVRDC and Thailand during 2010-2011. These genotypes were grown in Research and Development Farm of Lal Teer Seed Limited, Bashon, Gazipur during 2011-2012. The experiment was laid out in RCBD (randomized complete block design) with three replications. The seeds of these germplasm were sown in seedling tray. The media in the seedling tray have been prepared by using coconut coir, ash and decomposed cow dung at a ratio of $50 \%, 25 \%$ and $25 \%$ respectively. The media were boiled by steam for two hours. After cooling the media, the seeds were sown on 25 October, 2011. The seedlings at the age of 2 to 3 leaves were suitable for transplanting and this took 20-25 days after sowing. The transplantation of seedlings was done on November 20, 2011. Raised beds were prepared for transplanting. The width of raised bed was 4 meter. Plant to Plant distance was $2 \mathrm{~m}$ and row to row distance was $4 \mathrm{~m}$. Cow dung, Urea, TSP, MP, Gypsum, Zinc sulphate and Borax were applied @ 2kg, 66g, 92g, 88g, 65g, 1.65g and 3g per pit respectively. The entire amount of cow dung, TSP, Zinc sulphate, Gypsum, Borax and one-third of the urea and MP is applied at the time of final land preparation while the rest of the urea and MP is applied at two equal installments, 15 and 30days after transplanting. ${ }^{7}$ Data were collected on the following morphological traits associated with yield from randomly selected ten plants from each genotype for daysto first male flower opening, days to first female flower opening, number of flowers (male and female) per plant, fruit length and diameter $(\mathrm{cm})$, fruit weight $(\mathrm{kg})$, flesh thickness $(\mathrm{cm})$, brix $(\%)$, number of fruits per plant, number of seeds per fruit, 100 seeds weight $(\mathrm{g})$ and yield per plant $(\mathrm{kg})$. Genetic divergence was estimated following ${ }^{8}$ generalized distance $\left(D^{2}\right)$ extended by Rao. Tocher's $\operatorname{method}^{9}$ was followed for determining the cluster of genotypes in different group. All statistical analyses were carried out using GENSTAT 5.13 software program.

\section{Results and discussion}

The analysis of variance revealed (Table 2) that the significant variations among the genotypes for all the traits studied which indicated that the presence of notable genetic variability among the genotypes. The $\mathrm{D}^{2}$ values ranged from 7.14 to 25.75 between clusters I and III, The 21 genotypes fell into six clusters (Table 1). So, on the basis of degree of divergence $\left(\mathrm{D}^{2}\right.$ value $)$ the 21 genotypes were 
grouped into six clusters by the Toucher's method as described by Rao. ${ }^{9}$ Cluster III consisted of solitary individual genotype, cluster I and cluster VI of three accessions, cluster II and IV of six genotypes, while cluster V consisted of two genotypes, respectively. Genetic diversity is generally associated with geographical diversity, but the former is not necessarily directly related with geographic distribution. The genotypes within the same clusters although formed specific clusters but were originated from different geographical region of the world, which indicated the geographical distribution and genetic divergence did not follow the same trend which might be due to continuous exchange of genetic material among the countries of the world by the traders. Similar results were reported. They were grouped twenty four genotypes into nine clusters. The cluster VIII was the largest with seven genotypes followed by the cluster VII which had four genotypes. Parental lines from these two distance cluster may be used in hybridization programs, which is likely to produce wide variability with high heterotic effect. Two genotypes were formed in the clusters I, II, III, IV, V, VI. Cluster IX had only one genotype.

Bimal ${ }^{10}$ classified the divergence in 36 genotypes of bitter gourd into six clusters belonging 6, 6, 4, 3, 5 and 12 genotypes of bitter gourd. He also selected one, three and two parents from cluster I, IV and VI respectively for diallel analysis. ${ }^{11,12}$ studied the divergence in 27 genotypes of pumpkin and the genotypes were grouped into seven clusters containing $3,1,3,2,5,4$ and 9 genotypes of pumpkin, respectively. Rahman ${ }^{13}$ estimated considerable divergence in pumpkin. He grouped the 81 genotypes in to eight clusters containing $9,2,7,16,16,10,6$ and 15 genotypes of pumpkin, respectively. He also selected one, one, two, and four parents from cluster I, IV, VI and VIII respectively for diallel analysis. Banik ${ }^{12}$ also studied the genetic divergence in 26 genotypes of snake gourd and genotypes were grouped into seven distinct clusters contained 7, 5, 3, 3, 4, 3 and 1 genotypes of snake gourd, respectively. She also selected two, one, one, one and one parents from cluster I, III, IV, V and VI respectively for diallel analysis.

The clustering pattern of the genotypes under this study revealed that the genotypes collected from the same region were grouped into different clusters which indicated variation in genotypes irrespective of their site of collection. That is, the clustering pattern of the genotypes indicated that developing from the same location or common geographic origin did not form a single cluster. The genotypes belonging to different locations were included in the same cluster. This result indicated that geographic distribution and genetic divergence did not follow the same trend, which might be due to continuous exchange of genetic materials among the countries of the world. ${ }^{11,13}$ in pumpkin ${ }^{12}$ in snake gourd also found no variation among the genotypes due to geographical distribution; rather genotypes of same region were distributed in different clusters randomly which are similar to present study. So, the results, suggested that geographic isolation is not the only factor causing genetic diversity, but have different genetic architecture and this point should be considered in selecting parents for hybridization.

\section{Cluster distance}

The intra cluster distances were calculated from these inter genotypic distances as per. ${ }^{14}$ The averages of intra and inter cluster distance ( $\mathrm{D}^{2}$ values) are presented in Table 2. It was observed that inter group distances were always higher than those of intra group distance. The maximum inter cluster distance was observed between cluster I and cluster III (25.75) indicating wide range of genetic diversity between these two clusters which was followed by inter cluster distances between cluster I and cluster V (21.88) and cluster I and cluster IV (21.67). Intermediate or moderate inter cluster distance was observed between cluster V and VI (19.12) followed by cluster II and III (18.44), IV and V (17.05), II and V (16.24) and III and V (16.19). The lowest inter cluster divergence was observed between cluster III and IV (7.14) which was followed by cluster IV and VI (8.12), II and VI (9.73), III and VI (13.36) and II and IV (13.42), respectively. The intra cluster divergence varied from 0.00 to 1.38 which belonging one and three genotypes. Genotypes among the clusters separated by high $\mathrm{D}^{2}$ values could be used in hybridization program for obtaining wide spectrum of variations among the segregates. Similar reports were also made by Masud et al. ${ }^{11} \&$ Rahman $^{13}$ in pumpkin, Banik ${ }^{12}$ in snake gourd and $\mathrm{Bimal}^{10}$ in bitter gourd.

N.B. The bold figures denote intra-cluster distances.

\section{Cluster means}

The mean performances of different clusters for thirteen characters are shown in Table 3. Cluster I was composed of three genotypes and this cluster earned the lowest mean value for days to male flower opening (52.08) and days to female flower opening (54.8) followed by days to male flower opening (53.39), days to female flower opening (59.92) and days to female flower opening (60.17) in cluster VI and cluster II respectively. These characters are needed for early type of variety development. Cluster I also ranked first for number of seeds per fruit (162.77), flesh thickness (3.2) and for percentage of brix content of flesh (10.15\%) followed by cluster II and cluster VI. It also secured third position in case of number of fruits per plant (1.61) and yield (2.61). Yield is the ultimate goal for any crop production.

The cluster II had six genotypes and it produced the highest number of fruits per plant (1.72) followed by cluster I (1.61) and cluster VI (1.55). It also possessed highest ranked for number of female flower per plant (4.08), fruit length (20.11), flesh thickness (3.19). Cluster II secured second highest rank for fruit diameter (17.46), single fruit weight (2.94), yield per plant (4.83) and number of seeds per fruit (132.66). But it stood third rank for male flower opening (55.02), female flower opening (60.17), 100 seed weight (13.25) and brix content of flesh (6.76). Cluster III was formed by a single genotype. It possessed the lowest single fruit weight (1.41) which caused the lowest yield per plant (1.99) and also seed number per fruit (61.67). But it also produced the highest 100 seed weight which was due to bigger size of seed. So, commercial farmers would disagree with this genotype for less covering their land.

Cluster IV had six genotypes; remarkable feature was not noticed in this cluster for different characters. None of the genotypes included in cluster IV which showed the highest or lowest mean values considering thirteen different yield and yield contributing characters of pumpkin. The genotypes belonging to the cluster $\mathrm{V}$ showed the lowest values for number of fruits per plant (1.33), 100seed weight (8.38) and the percentage of brix content of flesh (2.83). The accessions under this cluster were late flowering in nature and required maximum days for first male (72.56) and female (75.71) flower opening. Rest of the characters showed moderate values. Yield is the ultimate goal for any crop production. The highest yield was 5.28 in clusters VI followed by 4.83 in cluster II, 2.61 in cluster I. The single fruit weight possessed highest weight $(3.6 \mathrm{~kg})$ in cluster VI followed by $2.94 \mathrm{~kg}, 1.91 \mathrm{~kg}$ and $1.76 \mathrm{~kg}$ in cluster II, cluster IV \&V and cluster I respectively. It also scored first and third highest in fruit diameter (19.45) and flesh thickness (3.07) respectively. 
Table I Distribution of 21 pumpkin genotypes in six cluster

\begin{tabular}{|c|c|c|c|}
\hline No. of cluster & Total no. of genotypes & Genotypes & Source \\
\hline \multirow{3}{*}{ I } & \multirow{3}{*}{3} & CM 20 & Thailand \\
\hline & & $\mathrm{CM} 02$ & Pabna \\
\hline & & CM 14 & Thailand \\
\hline \multirow{6}{*}{ II } & \multirow{6}{*}{6} & CM 01 & Lal Teer \\
\hline & & CM 18 & Gazipur \\
\hline & & $\mathrm{CM} 06$ & Thakurgaon \\
\hline & & CM 05 & Meherpur \\
\hline & & CM 09 & Rajshahi \\
\hline & & $\mathrm{CM} 21$ & Thakurgaon \\
\hline \multirow[t]{2}{*}{ III } & \multirow[t]{2}{*}{1} & $\mathrm{CM} 10$ & Gaibanda \\
\hline & & CM 07 & Pabna \\
\hline \multirow{5}{*}{ IV } & \multirow{5}{*}{6} & CM 16 & Jessore \\
\hline & & $\mathrm{CM} 03$ & Tangail \\
\hline & & CM 19 & Thailand \\
\hline & & CM 11 & Thailand \\
\hline & & CM 17 & Lal Teer \\
\hline \multirow{3}{*}{ V } & \multirow{3}{*}{2} & CM 04 & Jamalpur \\
\hline & & BARI Mistikumra-2 & BARI \\
\hline & & BARI Mistikumra-1 & BARI \\
\hline \multirow[t]{2}{*}{ VI } & \multirow[t]{2}{*}{3} & CM 08 & AVRDC \\
\hline & & CM 12 & Munshigonj \\
\hline
\end{tabular}

Table 2 Mean intra (bold) and inter cluster distances (D2-values) for 21 genotypes of pumpkin

\begin{tabular}{|c|c|c|c|c|c|c|c|c|}
\hline Cluster & & II & III & IV & v & VI & $\begin{array}{l}\text { No. of } \\
\text { genotypes }\end{array}$ & Genotypes \\
\hline 1 & 0.85 & 10.34 & 25.75 & 21.67 & 21.88 & 15.9 & 3 & $\mathrm{CM} 20, \mathrm{CM} 14, \mathrm{CM} 2$ \\
\hline II & & 1.13 & 18.44 & 13.42 & 16.24 & 9.73 & 6 & CM1, CM5, CM9, CM21, CM18, CM6 \\
\hline III & & & 0 & 7.14 & 16.19 & 13.36 & 1 & CM10 \\
\hline IV & & & & 0.87 & 17.05 & 8.12 & 6 & CM7, CM16, CM3, CM19, CM11, CM17 \\
\hline v & & & & & 1.03 & 19.12 & 2 & CM4, BARI Mistikumra-2 \\
\hline $\mathrm{VI}$ & & & & & & 1.38 & 3 & BARI Mistikumra-1, CM8, CM12 \\
\hline
\end{tabular}


Table 3 Cluster mean values for thirteen characters of 21 pumpkin genotypes

\begin{tabular}{llllllll}
\hline Characters & \multicolumn{7}{c}{ Clusters } \\
\cline { 2 - 7 } & I & II & III & IV & V & VI \\
\hline Days to male flower opening & 52.08 & 55.02 & 59.53 & 54.91 & 72.56 & 53.39 \\
Days to female flower opening & 54.8 & 60.17 & 66.57 & 61.98 & 75.71 & 59.92 \\
No. of male flowers per plant & 10.24 & 10.95 & 11.87 & 11.05 & 11.1 & 12.1 I \\
No. of female flowers per plant & 3.71 & 4.08 & 3.27 & 3.65 & 3.79 & 3.57 \\
Fruit length (cm) & 8.9 & 20.11 & 10.51 & 10.94 & 18.27 & 12.76 \\
Fruit diameter (cm) & 15.82 & 17.46 & 16.87 & 16.3 & 14.77 & 19.45 \\
Single fruit weight (kg) & 1.76 & 2.94 & 1.41 & 1.91 & 1.91 & 3.6 \\
Flesh thickness (cm) & 3.2 & 3.19 & 2.07 & 2.87 & 2.52 & 3.07 \\
No. of fruits per plant & 1.61 & 1.72 & 1.5 & 1.42 & 1.33 & 1.55 \\
No. of seeds per fruit & 162.77 & 132.66 & 61.67 & 87.72 & 81.68 & 110.08 \\
I00-seed weight (g) & 9.98 & 13.25 & 14.34 & 11.76 & 8.38 & 13.6 \\
Brix (\%) & 10.15 & 6.76 & 5.83 & 6.14 & 2.83 & 8.32 \\
Yield per plant (kg) & 2.61 & 4.83 & 1.99 & 2.56 & 2.47 & 5.28 \\
\hline
\end{tabular}

The seed yield per fruit (110.08) and 100 seed weight showed remarkable economic values. Similar results also noticed by Rahman ${ }^{13}$ in pumpkin, Banik ${ }^{12}$ in Snake gourd, Masud et al., ${ }^{11}$ in pumpkin et al., ${ }^{10}$ in bitter gourd. Beginning with all the classes mean values (Table 3 ) it was observed that, the genotypes belonging to the cluster VI were high yielding and therefore, this cluster ranked first in terms of single fruit weight and yield per plant and the genotypes of cluster I were early type with highest brix values. Other hand, cluster II possessed the highest number of female flower and fruits per plant with also second highest yield in pumpkin.

\section{Acknowledgements}

None.

\section{Conflict of interest}

The author declares no conflict of interest.

\section{References}

1. Katyal SL, Chadha ML. Vegetables Growing in India. India: Oxford and IBH Publishing Co New Delhi; 2000. p. 92-93.

2. Jahan TA, Islam AKMA, Rasul MG, et al. Heterosis of qualitative and quantitative characters in sweet gourd (Cucurbita moschata Duch.ex Poir). AJFAND online, Nairobi, Kanya. 2012;12(3):6186-6199.

3. Murty BR, Arunachalam V. The nature of genetic divergence in relation to breeding system in crop plants. Theory of Applied Genetics. 1966;44(5):211-214.

4. Ram J, Panwar DVS. Interspecific divergence in rice (Oryza sativa L.).
Indian J Genet. 1970;30:1-2.

5. Sachan KS, Sharma JR. Multivariate analysis of genetic divergence in tomato. Indian Journal of Genetics and Plant Breeding. 1971;31:86-93.

6. Jatasra DS, Paroda RS. Genetic divergence in wheat under different environmental conditions. Cereal Res Comm. 1978;6:307-317.

7. Bangladesh Agricultural Research Council. Fertilizer Recommendation Guide. Farm gate, New Airport Road, Dhaka, Bangladesh; 2012. 78 p

8. Mahalanobis PC. On the generalized distance in statistics. Proceedings of National Institute of Science India. 1936;2(1):49-55.

9. Rao CR. Advance statistical method in biometrical research. Ednl John wiley and sons New York. 1954;12(2):268-270.

10. Bimal CK. Morpho-Biochemical Diversity and Heterosis in Bitter gourd (Momordica charantia L) Dissertation. Dept. of Horticulture. BSMRAU Salna Gazipur Bangladesh; 2008

11. Masud MAT, Chowdhury MAZ, Hossain MA, et al. Multivariate analysis in pumpkin (Cucurbita moschata Duch ex Poir). Bangladesh Journal of Plant Breeding and Genetics. 1995;8(1-2):45-50.

12. Banik BR. Variability, gene action and heterosis in snake gourd (Trichosanthes anguina L) Dissertation. Dept. Genetics and Plant Breeding, BSMRAU Salna Gazipur, Bangladesh; 2003.

13. Rahman SMHE. Genetic Diversity, Combining ability and interrelationships among Yield Components in Sweet Gourd (Cucurbita moschata) Dissertation. Mymensingh, Bangladesh: Dept. of Horticulture Bangladesh Agricultural University; 2006.

14. Singh PK, Chaudhary BD. Biometrical methods in quantitative genetic analysis. Kalyani Publishers ND India; 1985. 318 p. 